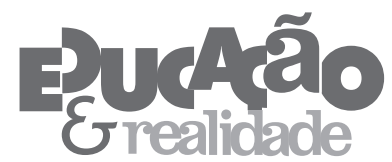

\title{
Limites e Possibilidades da Racionalidade Pedagógica no Ensino Superior
}

\author{
Francisco Kennedy Silva dos Santos \\ 'Universidade Federal de Pernambuco (UFPE), Recife/PE - Brasil
}

\begin{abstract}
RESUMO - Limites e Possibilidades da Racionalidade Pedagógica no Ensino Superior. Este artigo é resultado de uma investigação que tem por objeto o trabalho e a mobilização de saberes docentes, tendo como foco principal de análise os limites e as possibilidades da racionalidade pedagógica no Ensino Superior. A fundamentação teórica ancora-se em diversos estudos que procuram mapear as racionalidades que movem esses profissionais em situação de trabalho, tendo como referencial a prática. Diante da complexidade do objeto, utilizou-se da pesquisa qualitativa, uma vez que esta privilegia os significados dos sujeitos da pesquisa. Os resultados da pesquisa evidenciam que os docentes investigados, movidos por uma racionalidade técnica, possuem uma pedagogia própria pautada na transmissão do conteúdo.

Palavras-chave: Ensino Superior. Ensino de Geografia. Trabalho Docente. Racionalidade Pedagógica.
\end{abstract}

ABSTRACT - Limits and Possibilities of Pedagogical Rationality in Higher Education. This article is the result of a research that has as its object the work and the mobilization of teacher knowledge, having as the main focus of analysis the limits and possibilities of rationality pedagogical in Higher Education. The theoretical basis is anchored in the various studies that seek to map the rationalities that move these professionals in working situation, having as a reference to the practice. Considering the complexity of the object, it was used for qualitative research, since it focuses on the meanings of the research subjects. The research results show that the teachers investigated, powered by a technical rationality, have its own pedagogy based on transmission of the content.

Keywords: Higher Education. Geography Teaching. Teacher Work. Rationality Pedagogical.

Educação \& Realidade, Porto Alegre, v. 38, n. 3, p. 915-929, jul./set. 2013.

Disponível em: <http://www.ufrgs.br/edu_realidade> 
Limites e Possibilidades da Racionalidade Pedagógica no Ensino Superior

\section{Primeiras Imagens}

Muitas vezes, por estarem submetidos a uma dinâmica de trabalho que não os permite refletir ou atribuir significados às suas ações docentes, os professores são conduzidos por um tipo de racionalidade técnica, que infelizmente, para muitos, trabalhar dessa maneira é prova de honestidade moral e seriedade intelectual, mesmo que isto lhes custe a morte da arte de ensinar, do prazer de pensar, sentindo-se com a consciência tranquila e do dever cumprido (Carminati, 2006, p. 78).

A crítica à racionalidade técnica, que orientou e serviu de referência para a educação e socialização dos profissionais em geral e dos professores em particular durante grande parte do século XX, gerou uma série de estudos e pesquisas que têm procurado superar a relação linear e mecânica entre o conhecimento técnico-científico e a prática na sala de aula. Os limites e insuficiências dessa concepção levam à busca de novos instrumentos teóricos que fossem capazes de dar conta da complexidade dos fenômenos e ações que se desenvolvem durante atividades práticas para a produção e a mobilização de saberes na/para docência.

Historicamente, a profissão professor, segundo Imbernón (2004), caracterizava-se pelo predomínio do conhecimento das disciplinas à imagem e à semelhança de outras profissões. $\mathrm{O}$ autor segue afirmando que saber era possuir um conhecimento formal; portanto, quem obtivesse essas atribuições, também possuía a capacidade de ensinar. Nesta perspectiva, a competência política e pedagógica assume uma dimensão minoritária para a atividade docente, conforme apontado por Azambuja e Foster (2006). É possível inferir que este traço histórico da emergência da profissão docente tem comprometido a prática de ensino universitária, uma vez que nela se cristalizou a valorização da ação de ensinar como transmissão de conhecimentos.

Nas últimas décadas, o corpo docente universitário se constitui, em grande parte, por profissionais renomados, com sucesso em suas atividades profissionais, tendo como base a profissão paralela que exercem ou exerciam no mundo do trabalho, acreditando que quem sabe, automaticamente, sabe ensinar.

Estes profissionais, ao chegarem à universidade, trazem consigo inúmeras experiências do que é ser professor. Experiências estas adquiridas como alunos durante sua vida escolar, que lhe permitirão construir modelos que utilizarão por toda a sua carreira docente (Pimenta; Anatasiou, 2002).

Para Masetto (2002), a universidade e os professores universitários começam a se conscientizar de que a docência, como o exercício de qualquer profissão, exige capacitação própria e específica, não se restringindo a um diploma de bacharel, mestre ou doutor, ou ainda,

916 Educação \& Realidade, Porto Alegre, v. 38, n. 3, p. 915-929, jul./set. 2013. Disponível em: <http://www.ufrgs.br/edu_realidade> 
ao exercício de uma profissão. Exige tudo isto, além de outras competências próprias.

Ensinar é uma tarefa complexa na medida em que exige um conhecimento consistente acerca da disciplina ou das suas atividades, acerca da maneira como os estudantes aprendem, acerca do modo como serão conduzidos os recursos de ensino a fim de que se ajustem melhor às condições em que será realizado o trabalho etc. (Zabalza, 2004).

Conhecer bem a própria disciplina é uma condição fundamental, mas não é o suficiente. A capacidade intelectual do docente e a forma como abordará os conteúdos são muitos distintas de como o especialista o faz. Esta é uma maneira de se aproximar dos conteúdos ou das atividades profissionais pensando em estratégias para fazer com que os alunos aprendam.

É nesse cenário de incertezas que os docentes universitários são movidos por uma racionalidade instrumental alimentada pela experiência herdada de seus antigos mestres. Entretanto, diversos estudos procuram mapear as racionalidades que movem esses profissionais em situação de trabalho (Tardif; Lessard; Lahaye, 1991; Tardif; Lessard; Gauthier, 1998; Perrenoud, 1993; 1999; Therrien, 1996; 1997; Moreira; Lopes; Macedo, 1998; Tardif, 2000; 2002; Schön, 1995; 2000; Pimenta, 2006; Contreras, 2002; Sacristán, 1996; 1999; Zabalza, 2000; 2004; Zeichner, 1992; 1998; 2000).

É no caminho reflexivo-crítico, trilhado por esses autores, que procuramos nesta pesquisa desenvolver uma análise dos saberes docentes mobilizados no âmbito do trabalho dos professores universitários como profissionais reflexivos, tendo como referencial a prática docente. Para tanto, procuramos responder o seguinte problema: Qual a relação teoria-prática no trabalho docente desenvolvido pelos professores dos Cursos de Licenciatura em Geografia do Centro de Ciências e Tecnologia da Universidade Estadual do Ceará (UECE), em Fortaleza, sem formação pedagógica e como mobilizam os saberes no âmbito da docência?

Adotamos como categorias para a investigação o trabalho docente, o saber docente, a epistemologia da prática, a racionalidade pedagógica, a racionalidade técnica, a transformação pedagógica da matéria, o saber ensinar, a prática docente e a reflexividade, que permitem focalizar as relações dos professores com os saberes que dominam para poder ensinar e aqueles que ensinam.

Como objetivo geral da pesquisa, procuramos compreender os elementos constituintes da relação teoria-prática no trabalho docente desenvolvido no curso de licenciatura em Geografia e dos saberes e suas implicações resultantes para o processo de formação contínua do professor reflexivo-crítico. 
Limites e Possibilidades da Racionalidade Pedagógica no Ensino Superior

\section{Caminhos Trilhados e Trilhas que se Entrelaçam}

Diante da complexidade do objeto, optamos pela pesquisa qualitativa considerada o caminho mais indicado a trilhar, uma vez que esta privilegia os significados, experiências, motivos, sentimentos, atitudes e valores dos professores envolvidos com o fenômeno a ser investigado: a docência na Educação Superior na perspectiva de professores formados em áreas não pedagógicas. Este modelo de pesquisa condiz mais com o tipo de problema deste estudo, uma vez que "[...] ela aborda o conjunto de expressões humanas constantes nas estruturas, nos processos, nos sujeitos, nos significados e nas representações” (Minayo, 1994, p. 15).

A pesquisa qualitativa rompe com os parâmetros epistemológicos do paradigma positivista, incorporando em seu fazer, o sujeito e sua subjetividade; valorizando a construção peculiar das práticas cotidianas, que passam a ser vistas, não por seus produtos palpáveis, objetivados, quantitativos, mas pelo processo significativo de sua construção, onde se incorpora as representações, os significados e o sentido existencial elaborado (André, 2000).

A temática escolhida não é algo que possa ser quantificado, pois segundo Dias (2010, p. 81-82), incorpora significados e motivos que não podem ser “[...] reduzidos à operacionalização de variáveis" (Minayo, 1994, p. 18).

Assim, utilizaram-se dos seguintes procedimentos: a revisão bibliográfica; aplicação de questionários com questões abertas e fechadas; realização de entrevista semiestruturada e de explicitação; e a observação não participante.

O corpo docente do curso investigado possui 32 docentes responsáveis pelas disciplinas específicas do curso com titulação mínima de graduação, a saber: 3 pós-doutores, 15 doutores, 10 mestres e 4 graduados.

No que se refere ao regime de trabalho, encontramos nos cursos professores com dedicação exclusiva e horistas. No primeiro grupo, contabilizamos 18 docentes, enquanto que os horistas são representados por 14 docentes.

O número de professores que se dispuseram participar da pesquisa foi muito pequeno: 6 (seis) no total. A maior parcela de docentes alegou falta de tempo.

Para análise e tratamento dos dados, optou-se pela análise de conteúdos, conforme a proposta de Bardin (1995). A partir da orientação desse autor, na fase de organização dos dados, fizemos a transcrição integral do material coletado, com o objetivo de se resgatar todo o conteúdo temático gerado.

Agrupamos as falas dos sujeitos referentes a um mesmo assunto ora intitulando cada conjunto com palavras-chaves decorrentes dos próprios discursos, ora conservando o discurso sobre determinada te- 
mática. Os temas foram interpretados, buscando estabelecer relações com o referencial teórico que norteou este trabalho. Através dessa metodologia, buscamos identificar a significação dos dados coletados resultantes das entrevistas, questionários e das observações.

\title{
O Trabalho Docente e o Movimento de Profissionalização Docente
}

O trabalho docente é uma prática social que se faz no cotidiano dos sujeitos nela envolvidos e nesta prática social é que estes sujeitos se constituem como seres humanos, ao se apropriarem da experiência que se acumula de forma objetiva.

Os professores, ao atuarem com base em suas experiências anteriores ou em experiências aceitas e difundidas socialmente, estão evidenciando outra característica do pensamento cotidiano denominada de ultrageneralização (Heller, 1989).

Na heterogeneidade de seu trabalho o professor se encontra diante de situações complexas para as quais precisa encontrar respostas que podem ser criativas ou repetitivas dependendo de sua capacidade e habilidade de leitura da realidade e das possibilidades objetivas em que se realiza o trabalho. No entanto, quando a intervenção do professor é feita tendo em vista objetivos que se dirigem à busca de um resultado ideal, a atividade docente pode ser denominada práxis, uma vez que esta se caracteriza como uma atividade que pressupõe a idealização consciente por parte do sujeito que se propõe a interferir e a transformar a realidade.

O trabalho docente concebido como práxis, apresenta também uma dimensão criadora e, portanto se faz necessário explicitar melhor como esta criação ocorre, enquanto atividade humana. Nessa mesma perspectiva, Therrien (2006, p. 72) destaca que

\begin{abstract}
[...] o trabalho docente é entendido enquanto práxis transformadora de um sujeito (professor) em interação situada com outro sujeito (aluno), onde a produção de saberes e de significados caracteriza e direciona o processo de comunicação, dialogicidade e entendimento entre ambos na direção de uma emancipação fundada no ser social. Nessa concepção, o trabalho docente é visto como um processo educativo de instrução e de formação humana, através da mediação e da interação entre professor e alunos, a partir dos conteúdos do ensino em direção à construção de uma sociabilidade verdadeiramente humana onde sujeitos constroem sua identidade no seio de uma coletividade (Therrien, 2006, p. 72).
\end{abstract}

A atividade docente é uma prática social complexa que combina atitudes, expectativas, visões de mundo, habilidades e conhecimentos condicionados pelas diferentes histórias de vida dos professores.

Educação \& Realidade, Porto Alegre, v. 38, n. 3, p. 915-929, jul./set. 2013

Disponível em: <http://www.ufrgs.br/edu_realidade> 
Limites e Possibilidades da Racionalidade Pedagógica no Ensino Superior

É, também, altamente influenciada pela cultura das instituições onde se realiza. Como prática complexa, abarca dilemas sobre os quais nos vemos incitados a lançar um olhar como pesquisadores. Um desses dilemas diz respeito ao conhecimento profissional. A prática docente é, portanto, um lócus de formação e produção de saberes.

Os vários setores da atividade humana passaram por significativas mudanças que se caracterizam em novas configurações da ordem econômica e política relacionada ao conhecimento, às vinculações pessoais, às comunicações, entre outras, que trazem consequências muito diretas para a educação escolar. Tais mudanças afetam de maneira particular a formação de professores, área que se situa não só no âmbito do conhecimento, mas também da ética, em que estão em jogo entendimentos, convicções e atitudes que compõem o processo de preparação de crianças e jovens. Essa avalanche de mudanças, ao mesmo tempo em que se aproxima, distancia, torna similar, diferencia e reconfigura características, disposições de nações, instituições e profissões.

Nesse contexto, o trabalho docente assume diversas faces. Os aspectos mais visíveis do trabalho docente estão associados ao conceito de profissionalidade docente, que são requisitos essenciais da profissão do professor.

As discussões em torno da profissionalização apontam para a natureza complexa da profissão docente e para a necessidade de compreendê-la com suas características próprias, a partir da análise da atividade concreta dos professores em seus contextos de trabalho, no cotidiano escolar.

Nesta perspectiva, a profissionalidade refere-se a um conjunto de capacidades e saberes desenvolvidos pelos trabalhadores no desempenho de funções, num determinado momento histórico (Brezezinski, 2002). Saberes esses que evoluem e se ressignificam no exercício da profissão. Essas transformações ocorridas na vida dos professores é que levam à profissionalidade (D'Ávila; Sonneville, 2008).

Profissionalidade docente é, na expressão de Sacristán (1995, p. 65), “[...] a afirmação do que é específico na ação docente, isto é, o conjunto de comportamentos, conhecimentos, destrezas, atitudes e valores que constituem a especificidade de ser professor". São os aspectos, os traços profissionais construídos em relação ao trabalho docente que caracterizam, ou que identificam, profissionalmente o professor. Quando se diz “[...] que identificam [...]", não significa necessariamente afirmar: “[...] como são indicados [...]” os professores. Ou seja, a profissionalidade que se quer, ou que se defende teoricamente, nem sempre é a identidade que se tem socialmente.

Isaia e Bolzan (2007) veem a profissão docente como uma atividade específica que envolve um repertório de conhecimentos, saberes e fazeres voltados para o exercício docente, influenciada pela cultura acadêmica, em contextos sócio-culturais e institucionais, nos quais os professores estão inseridos.

920 Educação \& Realidade, Porto Alegre, v. 38, n. 3, p. 915-929, jul./set. 2013 Disponível em: <http://www.ufrgs.br/edu_realidade> 
Segundo Cunha (1999) é nesse contexto que o termo profissionalidade tem sido recorrente nos discursos dos educadores contemporâneos, que apresentam diferentes adjetivos aos professores com o intuito de explicitar a concepção que se projeta para o seu trabalho, tentando fugir da lógica liberal-mercadológica que tem envolvido a profissionalização docente.

Contreras (2002) refere-se à profissionalidade como qualidades da prática profissional dos educadores em função daquilo que requeira ofício educativo, bem como expressar valores e pretensões desejáveis buscando alcançar e desenvolver na profissão, a autonomia docente.

A profissionalidade não está alicerçada somente em dominar conhecimentos, saberes e fazeres de determinado campo, mas envolve a sensibilidade do docente como pessoa e profissional, no que se refere a atitudes e valores, levando-se em conta os saberes da experiência docente e profissional.

\section{Limites e Possibilidades da Racionalidade Pedagógica: uma breve fotografia}

Nas imagens construídas a seguir, que compõem uma única fotografia, procuramos inferir de forma crítica os percursos da prática docente dos sujeitos investigados, seus anseios e suas dificuldades em construir saberes pedagógico-docentes, na relação com os saberes específicos de sua área e na relação com os saberes da sua própria experiência docente.

\section{De Bacharel em Geografia à Docente: percursos de uma formação}

Ao questionarmos os docentes como se deu sua formação para a docência, todos os professores relacionaram essa formação com a troca de experiências com outros professores e com a experiência adquirida na prática.

Predomina entre os professores o entendimento de que a formação para a docência se dá na prática, pela convivência com outros professores. Tardif (2002) esclarece que cotidianamente, os professores partilham seus saberes uns com os outros através do material didático, dos macetes dos modos de fazer, dos modos de organizar a sala de aula, etc. De fato, os professores constroem seus saberes no decorrer de sua prática docente, no dia-a-dia de sala de aula, na superação dos desafios, na troca de experiência com seus pares.

Os relatos mostram que o cotidiano dos professores é marcado pela individualidade, sem qualquer referência a uma dimensão coletiva de trabalho. Segundo Abreu (1983), um indivíduo isolado não dispõe de elementos para se rever e se atualizar; é no diálogo, na reflexão conjunta, na troca de experiências e opiniões, na colaboração, que um 
Limites e Possibilidades da Racionalidade Pedagógica no Ensino Superior

ser se faz educador. Apesar de nos relatos haver a presença dos pares no desenvolvimento profissional, em nenhum momento parece haver um diálogo intencional na busca de um planejamento que vise à superação de dificuldades encontradas no cotidiano dos docentes. discussão:

Pimenta e Anastasiou (2002, p. 113) trazem contribuições a essa

Refletir coletivamente sobre o que se faz é pôr-se na roda, é deixar-se conhecer, é expor-se - o que fazemos com muita dificuldade, uma vez que, como docentes da Educação Superior, estamos acostumados a processos de planejamento, execução e avaliação das atividades de forma individual, individualista e solitária. Superar essa forma de atuação é processual: na vivência, o grupo vai criando vínculos e se posicionando. Haverá aqueles que prontamente aderem às atividades e outros que, em seu ritmo, vão se soltando e se expondo, a sim mesmos e aos grupos de trabalho (Pimenta; Anastasiou, 2002, p. $113)$.

Nóvoa (1995) afirma que a troca de experiências e a partilha de saberes consolidam espaços de formação mútua, nos quais cada professor é chamado a desempenhar, simultaneamente, o papel de formador e de formando.

\section{Navegando no Campo das Incertezas em Situações de Trabalho}

Entramos aqui, no espaço de ação dos docentes - a sala de aula, com o objetivo de caracterizar os mecanismos (procedimentos) de reflexividade crítica presentes em situações de aula, bem como de desvelar a racionalidade constituinte da gestão dos saberes dos docentes investigados.

Masetto (2001, p. 85) concebe a aula como “[...] o espaço e o tempo no qual e durante o qual os sujeitos de um processo de aprendizagem (o professor e alunos) se encontram para juntos realizarem uma série de ações [...]". Mas como os docentes bacharéis o fazem? Assim, acompanhamos o complexo cotidiano da sala de aula com o objetivo de identificar os saberes que os professores mobilizam nesse espaço-tempo do processo de ensino-aprendizagem.

As observações realizadas em sala de aula evidenciam que, embora alguns dos professores não tenham demonstrado reação à presença do pesquisador, em um bom número de vezes houve o argumento de que as atividades junto aos alunos naquela aula consistiriam em exposição oral de conteúdo e resolução de exercícios. Não haveria, portanto, o que observar. Na verdade, realiza-se a observação do que o outro permite. Mesmo nas aulas observadas, praticamente pouco se pode verificar do processo ensino-aprendizagem em si, tamanha é a preocupação do professor em divulgar assuntos alheios ao conteúdo de aula ou datas de provas. 
As aulas das disciplinas observadas são ministradas em sua maioria de forma expositiva, sendo alguns conceitos escritos no quadro; outras vezes, a aula consiste em leitura exaustiva de alguns parágrafos considerados importantes pelos professores, ou ainda da leitura alternada pelos alunos de parágrafo por parágrafo do texto seguido de comentários do professor, sem margem para questionamentos por parte dos discentes.

Nesse sentido, as aulas expositivas ocorriam com o objetivo de informar e representam formas econômicas e de controle da turma. Esse tipo de metodologia exige dos alunos alto nível de concentração durante todo o tempo das aulas. Há pouca interação entre professor e aluno.

Não defendemos aqui que a aula expositiva deveria ser abolida por estes ou outros professores. Corroboramos com Masetto (2005, p. 96-97), que a seu entender, não se trata de abolir a aula expositiva, mas sim de usá-la como técnica, isto é, quando ela for adequada aos objetivos que temos. Isso quer dizer que ela cabe, por exemplo,

[...] no início de um assunto para motivar os alunos a estudá-lo ou para apresentar um panorama do tema que será estudado posteriormente, ou como síntese de um estudo feito individual ou coletivamente, ao final dos trabalhos. Sempre usando de 20 a 30 minutos da aula (não mais do que isso), pois é o tempo no qual conseguimos manter a atenção dos alunos [...].

De acordo com Moraes (1997, p. 58), o modelo de aula universitária, ainda predominante é o de:

Dividir o conhecimento em assuntos, especialidades, subespecialidades, centrada no professor e na transmissão do conteúdo que, em nome da transmissão do conhecimento, continua vendo o indivíduo como uma tabula rasa, produzindo seres subservientes, obedientes, castrados em sua capacidade criativa, destituídos de outras formas de expressão e solidariedade. E uma educação "domesticadora", "bancária", segundo Paulo Freire, que "deposita" no aluno informações, dados e fatos, onde o professor é quem detém o saber, a autoridade, que dirige o processo e um modelo a ser seguido.

Este ideário indica os pressupostos epistemológicos nos quais o ensino superior se assenta. Neste sentido, Cunha (1999, p. 1) afirma que:

A forte presença do paradigma da ciência moderna na sociedade ocidental acabou por cristalizar a forma tradicional de currículo, vendo-a como uma única possibilidade de organização. Esta, resume-se na lógica presente no nosso cotidiano acadêmico: dos fundamentos da ciência para sua aplicação; da teoria para prática; do básico para o profissionalizante (Cunha, 1999, p. 1).

Educação \& Realidade, Porto Alegre, v. 38, n. 3, p. 915-929, jul./set. 2013.

Disponível em: <http://www.ufrgs.br/edu_realidade> 
Limites e Possibilidades da Racionalidade Pedagógica no Ensino Superior

Esta lógica de organização curricular que separa pensamento e ação é sustentada pela teoria de aprendizagem ambientalista/empirista que parte do pressuposto de que primeiro o sujeito deve adquirir conhecimentos para depois poder aplicá-los na prática e em situações específicas. Nesta concepção, a melhor forma de aprender é pela audição e registro das verdades científicas reconhecidas que, para serem adquiridas, precisam de exercícios de experimentação e memorização. A prática é entendida como comprovação da teoria, sendo que seu sucesso depende do grau de aproximação com o conhecimento já construído via conteúdos disciplinares.

Há uma mera definição de conceitos por parte dos docentes, evidenciando a ausência de um planejamento de aula, o que obriga o docente a falar o tempo todo, levando o aluno ao cansaço e desmotivação. $\mathrm{O}$ professor sente-se a vontade para elaborar aulas descontextualizadas, focando programas de aprendizagens meramente burocráticas e conteudistas - apenas informações -, para executar a gestão da matéria e da classe por intermédio de aulas expositivas - aulas copiadas que só ensinam o aluno a copiar - e para avaliar de maneira mecânica e reprodutivista, o que evidencia uma autonomia exagerada dos professores (Puentes; Aquino, 2008).

Um fato interessante a ser destacado nas aulas observados nos laboratórios de pesquisa foi a grau de tranquilidade do professor na condução da matéria de ensino comparado ao desconforto evidenciado em sala de aula. Questionados sobre essa diferença, os docentes afirmaram que foram treinados para a pesquisa e não para o ensino.

Face às nossas análises, observamos no decorrer de nossas investigações que, de forma geral, os docentes são movidos por uma racionalidade técnica que se funde em sua prática, e estes desprovidos de uma racionalidade prática em situação de trabalho, permeados pelas incertezas, não conseguem superar o hiato entre teoria e prática. Diante deste quadro, a racionalidade técnica apresenta-se como uma solução instrumental de problemas centrada na aplicação.

\section{Algumas Conclusões com Sentido de Recomeço}

Nesta pesquisa desenvolveu-se uma análise dos saberes docentes no âmbito do trabalho dos professores como profissionais reflexivo-críticos, que nos apontasse os elementos para identificação das racionalidades que movem a ação docente em situação de trabalho, especificamente, de docentes sem formação pedagógica.

A tese central deste estudo é: os professores sem formação específica para a docência mobilizam saberes em situação de prática - saberes experienciais oriundos de suas inter-relações; no entanto, esses saberes não dão conta das incertezas em situação de trabalho e isolados em um contexto não superam a falta de uma formação pedagógica para a docência. 
O estudo partiu da concepção de que a preparação didáticopedagógica é necessária para a formação docente cuja especificidade formativa é o que a caracteriza. Foi a análise das representações dos professores que nos permitiu, em primeiro lugar, conhecer os sentidos e significados pelos professores aos saberes docentes. Alem disso trouxe elementos para compreensão de como os bacharéis professores que não tiveram formação para a docência desenvolvem sua prática pedagógica.

Grande parte das representações que os professores de nossa pesquisa possuem sobre sua atividade profissional decorrem de uma cultura gestada no processo de construção do ensino superior brasileiro, cuja trajetória esteve sempre voltada para a formação profissional. Assim, o domínio do conteúdo específico da disciplina tem forte influência na atividade do bacharel professor, sendo este o saber que orienta sua prática.

Investigar a prática docente de professores não é tão simples, envolve todo um tecido complexo que foi tecido nos moldes da racionalidade técnica, principalmente quando os sujeitos observados são professores universitários.

O estado defensivo com que os sujeitos se comportavam diante de nossa presença em seu espaço de trabalho era claro. Mesmo não inseguros do conteúdo da matéria, tendo pleno domínio do conteúdo de sua disciplina, se sentiam incomodados pela falta do conhecimento pedagógico, entretanto esse fato não os impedia de continuar a dar sua aula. Imitar seus antigos mestres, constituía-se o mecanismo determinante e suficiente para transmitir e reproduzir o conteúdo disciplinar.

As análises dos resultados permitem afirmar que os docentes que atuam nos curso de licenciatura em Geografia apresentam deficiências pedagógicas que impedem, efetivamente, a transformação pedagógica da matéria e consequentemente a produção e mobilização situada de saberes, ficando sua ação restrita à transposição didática, de caráter normativo e mecânico, sem que esta transposição passe por inúmeras e profundas transformações. Portanto, torna-se necessário superar a crença de que para ser bom professor basta conhecer profundamente e conseguir transmitir com clareza determinado conteúdo, ou até mesmo como no caso da Educação Superior, ser um bom pesquisador.

A falta de uma formação pedagógica para a docência evidencia que somente o domínio dos saberes específicos não é suficiente para que os docentes pesquisados possam dar conta das incertezas de suas ações em situação de trabalho.

Constatamos, portanto, a partir de nossas observações que o saber experiencial e o saber específico da matéria não superam a falta de formação pedagógica para o exercício da docência, mesmo que os professores sejam peritos em sua área de formação inicial. Diante dessa situação, as aulas desses docentes baseiam-se, de modo geral, em dois grandes modelos, referenciados no que viram seus antigos mestres fa-

Educação \& Realidade, Porto Alegre, v. 38, n. 3, p. 915-929, jul./set. 2013.

Disponível em: <http://www.ufrgs.br/edu_realidade> 
Limites e Possibilidades da Racionalidade Pedagógica no Ensino Superior

zerem: os das aulas teóricas, em sala de aula, e os das aulas práticas, nos laboratórios de pesquisas, movidos por uma racionalidade técnica, instrumental.

Resumidamente, os achados dessa investigação nos permitiram concluir que: a) o professor-bacharel dos cursos investigados tem uma pedagogia própria pautada na transmissão do conteúdo; b) o pedagógico é visto como transferência de conteúdo; c) segundo suas representações os professores não consideram a formação pedagógica como base para a docência, mas sim os saberes da área específica da sua formação profissional.

Esses achados nos põem desafios de investigar modos de trabalhar a formação e a prática do docente de Educação Superior que permita a produção e a mobilização de saberes situados na docência.

Acredito que pensar uma nova racionalidade numa perspectiva intersubjetiva, como é o caso da Teoria da Ação Comunicativa, traz contribuições e uma resposta a esse desafio. Ao destacar essa teoria como uma alternativa metodológica de formação do docente universitário, torna-se necessário destacar algumas ideias que embasam tal afirmação.

A formação docente, tanto a inicial quanto a contínua, precisa ser consistente, precisa ser capaz de fornecer fundamentos teóricos e práticos para o desenvolvimento das capacidades intelectuais do professor, direcionando-o ao seu fazer pedagógico. Uma formação com bases na teoria habermasiana do agir comunicativo poderá dar conta da superação dicotômica entre teoria e prática, marca da racionalidade técnica, bem como de uma prática docente baseada na transmissão de conteúdo, conforme resultados da presente pesquisa.

Essa teoria, segundo Habermas (1987), possibilita compreender a formação do professor a partir do trabalho real, do trabalho corrente no contexto de trabalho, e não a partir do trabalho prescrito, superando a visão da racionalidade técnica e do senso comum que ainda vigora fortemente nas escolas e nas instituições formadoras.

Ainda a importância desse modelo para a formação docente está no fato de ele acentuar a primazia da aprendizagem pela atividade, considerando que ela ocorre por um processo de assimilação da experiência sociocultural e a atividade coletiva dos indivíduos e por um processo de internalização. O tornar-se professor é uma atividade de aprendizagem e, para isso, são requeridas capacidades e habilidades específicas. A aprendizagem estaria ligada aos fazeres que seriam o suporte do desenvolvimento do pensamento teórico.

Constato, de forma mais específica, que a aprendizagem para a formação do pensamento teórico-científico, objetivo final da atividade de aprendizagem, requer primeiramente que os professores da Educação Superior admitam que sua profissão necessita de duas especialidades: a de dominar os conteúdos específicos da matéria que ensina; a de 
dominar os modos de ensinar essa matéria para que os alunos aprendam. Em segundo lugar, o professor universitário precisar saber lidar pedagógico-didaticamente com o conteúdo de sua disciplina.

A minha aproximação com o tema desta investigação mostrou-me o quanto podemos aprender e o quanto ainda precisamos aprender a apreender. Aprender não apenas para nós mesmos, mas para compartilhar e contribuir para o processo de formação docente e, por consequência, para a formação de outras pessoas. Pessoalmente compreendo que eu e meus pares estamos no início de uma jornada; que este estudo é apenas um passo entre muitos outros a serem dados na direção daquilo que compreendo ser um professor reflexivo-crítico na busca exaustiva de um trabalho docente efetivo e situado, cujo produto maior seja a transformação pedagógica da matéria de ensino para a produção e mobilização de novos conhecimentos pelos docentes e discentes de Educação Superior, e que rompa com o paradigma positivista a partir de uma nova racionalidade - a comunicativa.

Recebido em 17 de janeiro de 2012 Aprovado em 19 de maio de 2012

\section{Referências}

ABREU. Maria Célia; MASETTO, Marcos Tarciso. O Professor Universitário em Aula: prática e princípios teóricos. São Paulo: Cortez, 1983.

ANDRÉ, Marli. Etnografia da Prática Escolar. 4. ed. Campinas: Papirus, 2000. 128p.

AZAMBUJA, Guacira; FOSTER, Mari Margarete dos Santos. Diferentes Dimensões da Formação e da Prática Docente: culturas, representações e saberes. Unirevista, São Leopoldo, v. 1, n. 2, p. 1-12, abr. 2006.

BARDIN, Laurence. Análise do Conteúdo. Tradução de L. A. Antero e A. Pinheiro. Lisboa: Edições 70, 1995.

BREZEZINSKI, Iria (Org.). Profissão Professor: identidade e profissionalização docente. Brasília: Plano, 2002.

CARMINATI, Celson João. Professores de Filosofia: crise e perspectivas. Itajaí: Universidade do Vale do Itajaí, 2006. 185p.

CONTRERAS, José. A Autonomia dos Professores. São Paulo: Cortez, 2002.

CUNHA, Maria Isabel da. Profissionalização Docente: Contradições e Perspectivas. In: VEIGA, Ilma Passos Alencastro; CUNHA, Maria Isabel da (Org.). Desmistificando a Profissionalização do Magistério. Campinas: Papirus, 1999. P. 127-148.

D’ÁVILA, Maria Cristina; SONNEVILLE, Jacques. Trilhas Percorridas na Formação de Professores: da epistemologia da prática à fenomenologia existencial. In: D’ÁVILA, Maria Cristina; VEIGA, Ilma Passos A. (Org.). Profissão Docente: novos sentidos, novas perspectivas. Campinas: Papirus, 2008. P. 23-44.

DIAS, Ana Maria Iorio. Leitura e (Auto)Formação: caminhos percorridos por docentes na Educação Superior. In: VEIGA, Ilma Passos Alencastro; VIANA, Cleide Maria Azevedo Quixadá. Docentes Para a Educação Superior: processos formativos. Campinas: Ed. Papirus, 2010. P. 71-100.

Educação \& Realidade, Porto Alegre, v. 38, n. 3, p. 915-929, jul./set. 2013.

Disponível em: <http://www.ufrgs.br/edu_realidade> 
Limites e Possibilidades da Racionalidade Pedagógica no Ensino Superior

HABERMAS, Jürgen. Conhecimento e Interesse. Rio de Janeiro: Guanabara, 1987.

HELLER, Agnes. O Cotidiano e a História. Rio de Janeiro: Paz e Terra, 1989.

IMBERNÓN, Francisco. Formação Docente e Profissional: formar-se para a mudança e a incerteza. São Paulo: Cortez, 2004.

ISAIA, Silvia Maria; BOLZAN, Dóris. Construção da Profissão/Professoralidade em Debate: desafios para a educação superior. In: CUNHA, Maria Isabel (Org.) Reflexões e Práticas em Pedagogia Universitária. Campinas: Papirus, 2007. P. $161-178$

MASETTO, Marcos Tarcísio. Atividades Pedagógicas no Cotidiano da Sala de Aula Universitária: reflexões e sugestões. In. CASTANHO, Sérgio; CASTANHO, Maria Eugênia (Org.). Temas e Textos em Metodologias do Ensino Superior. Campinas: Papirus, 2001.

MASETTO, Marcos Tarcísio (Org.). Docência na Universidade. Campinas, Papirus, 2002.

MASETTO, Marcos Tarcísio (Org.). Docência Universitária: a aula em foco. In: TEODORO, António; VASCONCELOS, Maria Lúcia. Ensinar e Aprender no Ensino Superior: por uma epistemologia da curiosidade na formação universitária. São Paulo: Cortez e Mackenzie, 2005. P. 79-108.

MINAYO, Maria Cecília de Sousa (Org.). Pesquisa Social: teoria, método e criatividade. Petrópolis: Vozes, 1994.

MORAES, Maria Cândida. O Paradigma Educacional Emergente. Campinas, SP: Papirus, 1997

MOREIRA, António Flávio; LOPES, Alice Casimiro; MACEDO, Elizabeth. Socialização Profissional de Professores: as instituições formadoras: relatório de pesquisa. Rio de Janeiro, UFRJ, 1998. 123 p.

NÓVOA, António. Os Professores e a sua Formação. Lisboa: Dom Quixote, 1995. PERRENOUD, Philippe. Práticas Pedagógicas, Profissão Docente e Formação: perspectivas sociológicas. Lisboa: Publicações Dom Quixote, Instituto de Inovação Educacional, 1993.

PERRENOUD, Philippe. Dez Novas Competências Para Ensinar. Porto Alegre: Artes Médicas, 1999.

PIMENTA, Selma Garrido; ANASTASIOU, Léa das Graças Camargo. Docência no Ensino Superior. São Paulo: Cortez, 2002.

PIMENTA Selma Garrido. Professor Reflexivo: construindo uma crítica. In: PIMENTA; Selma Garrido; GHEDIN, Luiz Evandro (Org.). Professor Reflexivo no Brasil: gênese e crítica de um conceito. 4. ed. São Paulo: Cortez, 2006. P. 17-52

PUENTES, Roberto Valdés; AQUINO, Orlando Fernandéz. A Aula Universitária: resultados de um estudo empírico sobre o gerenciamento do tempo. Linhas Críticas. UnB, Brasília, v. 14, n. 26, p. 111-128, jan./jun. 2008.

SACRISTÁN, José Gimeno. Tendências Investigativas na Formação de Professores. Transcrição e tradução de José Carlos Libâneo. In: ATAS DA 19a REUNIÃO ANUAL ANPED. Caxambu: ANPED, 1996. P. 12-27.

SACRISTÁN, José Gimeno. Poderes Instáveis em Educação. Tradução de Beatriz Afonso Neves, Porto Alegre: Artes Médicas, 1999

SCHÖN, Donald Alan. Formar Professores Como Profissionais Reflexivos. In: NÓVOA, António (Org.). Os Professores e sua Formação. Lisboa: Dom Quixote, 1995. P. 77-92

928 Educação \& Realidade, Porto Alegre, v. 38, n. 3, p. 915-929, jul./set. 2013 Disponível em: <http://www.ufrgs.br/edu_realidade> 
SCHÖN, Donald Alan. Educando o Profissional Reflexivo: um novo design para o ensino e a aprendizagem. Porto Alegre: Artmed, 2000.

TARDIF, Maurice; LESSARD, Claude; GAUTHIER, Clermont. Formation des Maîtres et Contexts Sociaux: perspectives internationals. Paris: Presses Universitaires de France, 1998.

TARDIF, Maurice; LESSARD, Claude; LAHAYE, Louise. Os Professores Face ao Saber: esboço de uma problemática do saber docente. Teoria e Educação, Porto Alegre, n. 4, p. 215-233, 1991.

TARDIF, Maurice. Saberes Profissionais dos Professores e Conhecimentos Universitários: elementos para uma epistemologia da prática profissional dos professores e suas consequências em relação à formação para o magistério. Revista Brasileira de Educação. ANPED, São Paulo, n. 13, p. 5-24, jan./abr. 2000. Disponível em: <http://www.anped.org.br/rbe/rbedigital/RBDE13/RBDE13_05_ MAURICE_TARDIF.pdf $>$. Acesso em: 15 nov. 2011.

TARDIF, Maurice. Saberes Docentes e Formação de Professores. São Paulo: Vozes, 2002.

THERRIEN, Jacques. Trabalho e Saber: a interação no contexto da pós-modernidade. In: MARKERT, Werner (Org.). Trabalho, Qualificação e Politecnia. Campinas: Papirus, 1996. P. 53-70.

THERRIEN, Jacques. Saber de experiência, Identidade e Competência Profissional: como os docentes produzem sua profissão. Contexto \& Educação, Ijui, v. 12, n. 48, p. 7-36, 1997.

THERRIEN, Jacques. Os Saberes da Racionalidade Pedagógica na Sociedade Contemporânea. Revista Educativa, Goiânia, v. 9, n. 1, p. 67-81, 2006.

ZABALZA, Miguel. El Papel de los Departamentos em La Mejora de La Calidad de La Docencia em La Universitária. Revista Interuniversitaria de Formación Del Profesorado, Zaragoza, v. 38, n. 4, p. 45-68, 2000.

ZABALZA, Miguel. O Ensino Universitário: seu cenário e seus protagonistas. Trad. Ernani Rosa. Porto Alegre: Artmed, 2004.

ZEICHNER, Kenneth. O Pensamento Prático do Professor. In. NÓVOA, Antonio. Os Professores e sua Formação. Lisboa: Dom Quixote, 1992. P. 115-138.

ZEICHNER, Kenneth. Para Além da Divisão Entre Professor-Pesquisador e Pesquisador-Acadêmico. In: GERALDI, C.M.G (Org.). Cartografia do Trabalho Docente. Campinas: Mercado de Letras, 1998. P. 207-236.

ZEICHNER, Kenneth. Formação de Professores: contato direto com a realidade da escola. Presença Pedagógica, Belo Horizonte, v. 6, n. 34, p. 5-15, jul./ago. 2000.

Francisco Kennedy Silva dos Santos é doutor em Educação. Professor e Pesquisador do Programa de Pós-graduação em Geografia da Universidade Federal de Pernambuco. Líder do Grupo de Pesquisa Educação, Cultura Escolar e Inovação - GPECI/CNPQ.

E-mail: francisco.kennedy@ufpe.br 